\title{
Lateral connections synchronize population activity in a spiking neural network model of midbrain superior colliculus
}

\author{
Bahadir Kasap*, John van Opstal \\ From 24th Annual Computational Neuroscience Meeting: CNS*2015 \\ Prague, Czech Republic. 18-23 July 2015
}

Saccades are rapid and ballistic eye-head gaze shifts between points of interest in the visual field. They are crucial for gathering high-resolution visual information. The midbrain superior colliculus (SC) generates saccadic eyemovement commands for downstream oculomotor circuits. It contains an eye-centered, gaze-motor map that relates the location of a Gaussian-shaped neural population to the intended movement vector. The gaze-motor map mediates the spatiotemporal transformation for eyehead orienting gaze shifts to peripheral targets [1]. Electrophysiological recordings have shown that SC neurons exhibit some remarkable activity properties that depend on both their anatomical position and the resulting saccade trajectory [2].

Here, we propose a biologically plausible spiking neural network model that is constrained by the observed firing patterns of real SC neurons for visually evoked saccades. The functional two-dimensional network model reproduces the spike trains of single neurons in recorded SC populations for saccades with different amplitudes and directions.

The network model consists of a 2D grid of neurons, representing the gaze-motor map. The adaptive integrateand-fire neurons [3] portray the observed site-dependent bursting profiles of individual SC neurons through distinct intrinsic biophysical properties, whereas Mexican-hat shaped lateral connections ensure the observed synchronized population activity by a soft winner-takes-all mechanism.

We argue that our model offers a basis for neuronal algorithms of spatiotemporal transformations and bioinspired optimal control signal generators.

\footnotetext{
* Correspondence: b.kasap@donders.ru.nl

Donders Institute for Brain, Cognition and Behaviour; Dept. Biophysics, Radboud University Nijmegen, Nijmegen, the Netherlands
}

\section{Acknowledgements}

This work is funded by the European Commission through FP7 Marie Curie ITN project "NETT" (Grant nr. 289146) (BK) and the Radboud University Nijmegen (AvO).

\section{Published: 18 December 2015}

\section{References}

1. Ottes FP, van Gisbergen JAM, Eggermont JJ: Visuomotor fields of the superior colliculus: a quantitative model. Vision Research 1986, 26(6):857-873.

2. Goossens HHLM, van Opstal AJ: Optimal control of saccades by spatialtemporal activity patterns in the monkey superior colliculus. PLoS Computational Biology 2012, 8(5):e1002508.

3. Brette R, Gerstner W: Adaptive exponential integrate-and-fire model as an effective description of neuronal activity. Journal of Neurophysiology 2005, 94(5):3637-3642.

\section{doi:10.1186/1471-2202-16-S1-P273}

Cite this article as: Kasap and van Opstal: Lateral connections synchronize population activity in a spiking neural network model of midbrain superior colliculus. BMC Neuroscience 2015 16(Suppl 1):P273.

\section{Submit your next manuscript to BioMed Central and take full advantage of: \\ - Convenient online submission \\ - Thorough peer review \\ - No space constraints or color figure charges \\ - Immediate publication on acceptance \\ - Inclusion in PubMed, CAS, Scopus and Google Scholar \\ - Research which is freely available for redistribution

C Biomed Central

(c) 2015 Kasap and van Opstal This is an Open Access article distributed under the terms of the Creative Commons Attribution License (http://creativecommons.org/licenses/by/4.0), which permits unrestricted use, distribution, and reproduction in any medium, provided the original work is properly cited. The Creative Commons Public Domain Dedication waiver (http://creativecommons.org/ publicdomain/zero/1.0/) applies to the data made available in this article, unless otherwise stated. 